"This is an accepted manuscript of an article published by BMJ Publishing Group in British Journal of Sports Medicine, available online at http://dx.doi.org/10.1136/bjsports-2016$\underline{096996}$ It is not the copy of record."

\title{
Evidence in support of the call to ban the tackle and harmful contact in school rugby: a response to World Rugby
}

\author{
Allyson M Pollock, Adam John White, Graham Kirkwood
}

\begin{abstract}
In a paper published in BJSM (June 2016), World Rugby employees Ross Tucker and Martin Raftery and a third coauthor Evert Verhagen took issue with the recent call to ban tackling in school rugby in the UK and Ireland. That call (to ban tackling) was supported by a systematic review published in BJSM. Tucker et al claim that: (1) the mechanisms and risk factors for injury along with the incidence and severity of injury in youth rugby union have not been thoroughly identified or understood; (2) rugby players are at no greater risk of injury than other sports people, (3) this is particularly the case for children under 15 years and (4) removing the opportunity to learn the tackle from school pupils might increase rates of injuries. They conclude that a ban 'may be unnecessary and may also lead to unintended consequences such as an increase in the risk of injury later in participation.' Here we aim to rebut the case by Tucker et al. We share new research that extends the findings of our original systematic review and meta-analysis. A cautionary approach requires the removal of the tackle from school rugby as the quickest and most effective method of reducing high injury rates in youth rugby, a public health priority.
\end{abstract}

\section{Background}

Being cautious in order to protect vulnerable people, such as children, from harm is an acknowledged policy approach.1 On 1 March 2016, UK and Ireland Ministers for Sport, Education and Health were sent a letter asking them to remove the tackle and other forms of harmful contact from school rugby. 2 In June 2016, two World Rugby employees Ross Tucker and Martin Raftery and a third coauthor Evert Verhagen wrote in BJSM that such action 'may be unnecessary and may also lead to unintended consequences such as an increase in the risk of injury later in participation'.3 Tucker et al make three key statements:

1. 'With respect to injury surveillance in Rugby Union, particularly among youth players, it must be recognised that neither the incidence nor severity of injury have been thoroughly identified and understood, and thus nor have the specific mechanisms and risk factors for injury'.

2. 'The risk of participation in Rugby Union, while warranting focus and continued efforts for primary injury prevention, does not stand out beyond that of other popular sports' and 'up to the period of adolescence (age 15 years), the risk of injury in Rugby Union is low and to other major sports'.

3. Removing the tackle from school rugby may increase injuries later in life when tackling is introduced to the game by denying 'the need and opportunity to many young players to begin learning a skill set which evidence suggests is both effective (for performance) and protective later in their rugby playing careers'. They add such a ban 'may be unnecessary and may also lead to unintended consequences such as an increase in the risk of injury later in participation'. 
"This is an accepted manuscript of an article published by BMJ Publishing Group in British Journal of Sports Medicine, available online at http://dx.doi.org/10.1136/bjsports-2016$\underline{096996}$ It is not the copy of record."

Tucker et al make a number of factual errors when stating the data on risk; they also reinterpret the call for action in school rugby (which UK schools are responsible for under the physical education guidelines of the respective countries' Departments for Education) as a more general call for action in youth rugby that includes club and community rugby, which is not under the jurisdiction of the government.4

\section{Fuller and Drawer's model for risk management in sport}

Tucker et al draw on Fuller and Drawer's model for risk management in sport (see table 1)3 5 and for this reason we use this framework to situate and address Tucker's arguments.

Risk assessment Identification of risk factors and how these impinge on participants

Tucker et al argue that 'With respect to injury surveillance in Rugby Union, particularly among youth players, it must be recognised that neither the incidence nor severity of injury have been thoroughly identified and understood, and thus nor have the specific mechanisms and risk factors for injury'. Event-based extrinsic risk factors involving contact or collision, such as the tackle, are well-established risk factors for injury in rugby.6-12

Tucker et al acknowledge that the tackle is 'most injurious, accounting for between $50 \%$ and $70 \%$ of injuries in all forms of the game' and that 'available evidence from the community and youth setting identifies the tackle as the most injurious game event'. 3 Studies consistently and repeatedly show the tackle to be the most injurious phase of play across all age grades of children playing full contact rugby.13 14

Tucker's claim that 'the specific mechanisms and risk factors for injury' have not been 'thoroughly identified and understood' in this context is puzzling. Fuller and Drawer define a risk factor as 'a condition, object or situation that may be a potential source of harm to people' whereas risk is defined as 'the probability or likelihood' that such a risk factor will lead to harm.5 Risk factors might be situational (eg, facilities, equipment) or event based (eg, tackling) and can be either intrinsic (eg, age, physicality) or extrinsic (eg, laws of the game). From a public health perspective, it is not necessary to understand intrinsic player risk factors such as player physique or behaviour 15 when extrinsic risk factors are so clearly established.

In rugby union in England, the tackle is first introduced in the under nine game, after which it becomes a full part of the game.4 Younger children may be at more risk of all tacklerelated injuries than older children. Burger et al found that tournament players within the under 13 age grade had a higher probability of both all tackle-related injuries and time-loss tackle-related injuries than those in the under 18 age grade.16 Other research has found the proportion of tackle-related injuries of all injuries consistent across age ranges for head, face and neck injuries where a high percentage of injuries attributable to the tackle is evident for all ages: under 13 (50\%), under 15 (53\%), under 18 (45\%) and under 20 (49\%).13 
"This is an accepted manuscript of an article published by BMJ Publishing Group in British Journal of Sports Medicine, available online at http://dx.doi.org/10.1136/bjsports-2016$\underline{096996}$ It is not the copy of record."

The tackle is responsible for most concussions in youth rugby, a frequent injury contributing between $2.2 \%$ and $24.6 \%$ of all youth rugby injuries. 6 A systematic review of concussion in youth rugby7 found one study analysing concussion and phase of play: the study of 121 boys' and girls' US high school rugby clubs found that $65 \%$ of all concussions were associated with the tackle.17 In the English adult community rugby union game, the tackle has been found to be associated with $64 \%$ of all head injuries and $74 \%$ of all concussions. 18

Rates of match play concussion have been recorded as rising in both the professional and community adult rugby union game. In the 2014-2015 professional season in England, there were 13.4 concussions recorded per 1000 player-hours for matches up from 5.1 per 1000 player-hours in 2011-2012,19 whereas the rate was 2.63 per 1000 player-hours in community match rugby in 2014-2015 compared with 1.37 per 1000 player-hours in 20112012.18 An increasing awareness of concussion in the professional game by players, coaches, referees and medical staff is thought to explain some of the increase in rates.19 However, according to Roberts et al, in the community game there is likely to be underreporting of concussion 'through a lack of player awareness and/or unwillingness of players to report symptoms to club staff '.18 There are no equivalent surveillance projects as yet in school or club child rugby settings. Consensus statements on concussion including definitions of concussion diagnosis and return to play guidelines date from the first consensus conference in Vienna in 2001 and most recently the fifth conference in Berlin in 2016, but there is concern over how well these guidelines are adhered to.20 21

Concussion can lead to long-term harms. A Swedish study of over a million individuals under the age of 26 years identified 104290 with a prior traumatic brain injury (TBI). Compared with their unaffected siblings, those with mild TBI (concussion) were more likely to be in receipt of a disability pension or welfare payments, to have had more psychiatric inpatient admissions or outpatient visits, to die younger and to have lower educational achievement $(p<0.05$ for all).22 A recent study of 294 paediatric sports-related concussion patients in the USA found that girls were three or four times more likely to experience postconcussive symptoms lasting $>28$ days than boys, 23 a particular concern given the Rugby Unions' focus on increasing the number of female rugby players. 24 Head injury more generally has also been found to be associated with an increased risk of dementia and Alzheimer's disease. 25

\section{Incidence and estimation of risk}

Tucker et al state: i) 'neither the incidence nor severity of injury have been thoroughly identified and understood"; ii) "the risk of participation in Rugby Union, while warranting focus and continued efforts for primary injury prevention, does not stand out beyond that of other popular sports"; and this is particularly the case "up to the period of adolescence (age 15 years)" where "the risk of injury in Rugby Union is low and comparable to other major sports'.

Is it true that neither the incidence nor severity of injury has been thoroughly identified and understood? 
"This is an accepted manuscript of an article published by BMJ Publishing Group in British Journal of Sports Medicine, available online at http://dx.doi.org/10.1136/bjsports-2016$\underline{096996}$ It is not the copy of record."

There are no comprehensive injury surveillance systems for sports and other injuries in the UK and this needs to be rectified. 2627 However, the high risks and rates of injury in rugby are well established and consistently high across many studies throughout the world, notwithstanding the considerable heterogeneity in study design, differences in injury definitions used and differences in magnitude of effect.

Tucker et al criticise the systematic review by Freitag et al 6 on the grounds that it overstated the level of injury risk in the youth game because (1) the time-loss definition of injury used in the men's professional game was not applied and (2) analysis combined studies with different age groups to produce pooled rates of injury. We address each of these criticisms in turn.

(1) Would applying the time-loss definition used in the professional game change the findings of the Freitag review6?

Tucker et al claim that '... if the definition of injury was brought in line with the time-loss definition (>24 hours absence from match play or training after the day of injury) that has been adopted by the majority of well-established injury surveillance studies in the professional game, then the reported injury incidence in the youth Rugby playing cohort would be lower'. We reanalysed the evidence for the youth game, using a time-loss definition of $>24$ hours absence from match play or training after the day of injury and show an even higher rate of injuries in the youth game than those calculated in the earlier paper by Freitag et al. Our analysis is detailed below.

Freitag et al used the injury definitions for rugby union approved by the council of the International Rugby Board (IRB) in 2007 (now called World Rugby) 28 to calculate two pooled incidence figures for match injuries. The first rate was for injuries sustained by the youth player during a match 'irrespective of the need for medical attention or time-loss from rugby activities' from five studies of 26.7 (95\% confidence interval (Cl) 13.2 to 54.1) injuries per 1000 player-hours, equivalent to a $28.4 \%$ (95\% Cl $15.2 \%$ to $49.1 \%$ ) risk of a child being injured over the course of a season; the other rate measured severity under the timeloss definition of 'a player being unable to take a full part in future rugby training or match play' for at least 7 days from eight studies of 10.3 (95\% Cl 6.0 to 17.7) injuries per 1000 player-hours, equivalent to a $12.1 \%$ ( $95 \% \mathrm{Cl} 7.2 \%$ to $19.8 \%$ ) risk of a child being injured over the course of a season.

Tucker et al criticise Freitag et al for comparing the rate calculated under the IRB all injury definition of 26.7 ( $95 \% \mathrm{Cl} 13.2$ to 54.1) injuries per 1000 player-hours with the match injury incidence figure calculated by Williams et al of 81 (95\% Cl 63 to 105) injuries per 1000 player-hours for professional men's rugby union 12 under the time-loss definition of injury of $>24$ hours absence from match play or training after the day of injury.12

Tucker et al claim that if Freitag et al had applied Williams et al's definition of injury for professional players then the rate calculated would have been lower. We have recalculated a new pooled incidence rate based on the $>24$ hours definition for the studies used by Freitag et al. Two studies used in Freitag et al's meta-analysis use a comparable injury 
"This is an accepted manuscript of an article published by BMJ Publishing Group in British Journal of Sports Medicine, available online at http://dx.doi.org/10.1136/bjsports-2016$\underline{096996}$ It is not the copy of record."

definition to that used by Williams et al, one by Haseler et al where data were analysed from an injury surveillance programme carried out at an English community rugby club over the course of the season that included 210 male players from under 9 (child will have ninth birthday during the academic year) to under 17 age grades29; and one by PalmerGreen et al which analysed data from a two-season study of 250 male youth rugby union players aged 16-18 years from 12 English Premiership academies and 222 similarly aged boys from seven senior school rugby union teams.14 Combining the results from these two studies in a meta-analysis gives a pooled incidence of 34.6 injuries per 1000 player-hours ( $95 \% \mathrm{Cl} 25.0$ to 47.8 ). The time-loss definition of $>24$ hours absence from match play or training after the day of injury gives a higher rate of injury than that calculated for all injuries irrespective of medical attention or time loss from play. The injury rates may be higher because the studies may have included players at a higher level.14 Our reanalysis shows that the rate of injuries has not been overstated using the original definition.

\section{(2) Did combining ages overstate injury risk?}

Tucker et al claim that combining studies across different age groups to produce pooled rates of injury overstates the injury risk in the youth game. 6 We have reanalysed the data using narrower age bands to show that the rates and risks are high across all ages in youth and have not been overstated in the youth game.

The rate of injury in youth rugby increases with age although not linearly. $6830 \mathrm{An}$ australian study found head, face and neck injuries requiring a week away from games doubled from 11.8 ( $95 \% \mathrm{Cl} 8.9$ to 15.5 ) to 22.3 (95\% Cl 18.3 to 27.1 ) injuries per 1000 player-hours between the under 13 and under 15 game13 and in New Zealand a 25\% increase in injuries resulting in attendance at an injury clinic, from 20.0 to 25.7 injuries per 1000 player-hours, has been found between the under 13 game and under 15 game.31

In our work, we have acknowledged that studies of rugby injury are highly heterogeneous because of differences in injury definitions, who diagnoses and records the injuries and their level of medical qualification and expertise, study setting, age of participants and age grades used by the rugby playing authorities. Age is therefore just one of many factors leading to a high degree of heterogeneity making cross-study comparisons difficult, but not impossible. These limitations do not negate the validity of trying to give some sense of injury rates across youth rugby so long as any meta-analysis is presented with the above caveats. Injury rates are high, and the issue is around magnitude, that is, how high. Many studies give injury rates across broad as well as narrow age ranges in youth rugby.17 29 32-36 Freitag et al acknowledged a 'high degree of heterogeneity' in their paper and also gave $95 \%$ estimated predictive intervals for their results to estimate the uncertainty in predicting the true effects in future studies with characteristics drawn from the heterogeneous studies explored in the meta-analysis. 6 Full details of each study included in the pooled incidence figure were given and study limitations were further acknowledged in the limitations section. 6

Additionally, under-reporting of some injuries, particularly concussion, is an issue 36 as is changing conduct of youth rugby in terms of rules and player behaviour. Children and 
"This is an accepted manuscript of an article published by BMJ Publishing Group in British Journal of Sports Medicine, available online at http://dx.doi.org/10.1136/bjsports-2016096996 It is not the copy of record."

coaches may mirror the evolution of the professional game in terms of increasing physicality and rates of injury.37-40 These issues should be taken into account when combining studies from different eras or attempting to generalise their findings.

Freitag et al carried out the meta-analysis across all ages within single injury definitions. To address Tucker's concern with respect to age combinations, we have reanalysed the studies included in the Freitag et al meta-analysis using narrower age ranges; the results are presented in table 2 . The few studies available which permit analysis of narrow age ranges in our reworked meta-analysis show high rates of injury in all age groups, young and old. For under 14 s and younger, $18.6 \%$ (95\% Cl $12.8 \%$ to $26.6 \%)$ were likely to be injured in a season and $9.0 \%$ (95\% $\mathrm{Cl} 2.3 \%$ to $31.5 \%$ ) severely enough to be away from play for at least a week. For the under $15 \mathrm{~s}$ and older, $25.0 \%(95 \% \mathrm{Cl} 21.6 \%$ to $28.9 \%)$ were likely to be injured in a season and $19.5 \%$ (95\% Cl $4.1 \%$ to $67.6 \%$ ) severely enough to be away from play for at least a week. Notwithstanding study heterogeneity and wide estimated predictive intervals where available along with variation in estimates, it is clear that the rates and risks of injury are high across the age ranges in youth rugby and that the risk of injury has not been overstated.

Does the risk of participation in rugby union stand out beyond that of other popular sports and is the risk of injury in rugby union low and comparable to other major sports?

Medical experts working for the Rugby Football Union (RFU) state that 'rugby union has a relatively high risk of injury compared with other team sports', and that 'there is a growing body of literature showing that injury incidence in rugby union is similar to that of other full contact sports such as rugby league, American football and Australian Rules Football'.41 In collision sports, which the RFU terms full contact sports, 'athletes purposely hit or collide with each other or with inanimate objects (including the ground) with great force'.42 Rugby union and rugby league are the most frequently played collision sports in UK schools 43 and many schools make rugby compulsory.44 Our focus is on what can be done by schools and responsible state bodies to reduce the risk of injury in rugby.

Tucker et al incorrectly report the results of a between-sport comparison in children aged $6-15$ years by Pringle et al,35 claiming netball had the highest rate of injuries. Tucker et al confuse the injury rate for rugby league with that for netball; the correct figures are 24.5, 15.5 and 13.0 injuries per 1000 player-hours for rugby league, rugby union and netball, respectively. 35

We refer Tucker et al to two systematic reviews which conclude that collision sports have higher rates of injury than other sports. Pfister et al identified rugby as having a significantly higher rate of concussion than any other youth (under 18s) contact or collision team sport.45 Spinks and McClure identified ice hockey, another collision sport, as having the highest rate of injury of any sport in children under the age of 16 years, despite varying definitions of injury, heterogeneity in study methods and a wide range of injury rates.46 Also, Bleakley et al, in their systematic review of rugby union injuries in children aged 12-18 years, cite evidence in the discussion that the risk of injury in rugby union in children aged 12-18 years is higher than other sports including football (soccer) and basketball and that 
"This is an accepted manuscript of an article published by BMJ Publishing Group in British Journal of Sports Medicine, available online at http://dx.doi.org/10.1136/bjsports-2016$\underline{096996}$ It is not the copy of record."

the prevalence of severe injury in adolescent rugby players was lower than or comparable to high school American football, football and wrestling athletes. 8 Spinks and McClure also found football (soccer) to have the lowest rate of injuries.46

Taking all these results together, it is difficult to see how Tucker et al arrive at the conclusion that the risk of participation in rugby union doesn't stand out beyond that of other popular sports. Our conclusion, in line with other commentators, and confirmed by the evidence, is that rugby, along with other collision sports, has a high risk of injury compared with other non-collision contact sports and a higher risk of concussion than any team sport, either collision or non-collision.41 45 47-50 Rugby is by far the most played collision sport in UK schools; therefore, any public health approach to lower the high rates of sport injury in children needs to look seriously at rugby and how to reduce that rate of injuries, including concussion.

\section{Risk mitigation}

Tucker et al argue that removing the tackle from school rugby may increase injuries later in life when tackling is introduced to the game by denying 'the need and opportunity to many young players to begin learning a skill set which evidence suggests is both effective (for performance) and protective later in their rugby playing careers". They add such a ban "may be unnecessary and may also lead to unintended consequences such as an increase in the risk of injury later in participation'.

Will removing the tackle from school rugby lead to an increased risk of injury later in participation?

Tucker et al misreport the findings of Mclntosh et al as attributing tackle technique to lower injury rates in younger players.51 McIntosh et al found that younger (under 15 years) players were more likely to use a passive shoulder tackle whereas older players were more likely to use an active shoulder tackle; but separately they found a significantly lower risk of tackle game injury in younger players than elite players. They conclude, however, that no specific tackle technique was associated with a significantly increased risk of injury. They analysed a total of 6618 tackle events, of which 81 resulted in injury, and found no statistical evidence of any difference in the odds of receiving an injury during an active shoulder tackle compared with any one of passive shoulder tackle, jersey tackle, ankle tap or smother ( $p>0.05$ for each); the only association with technique was an increased risk of injury when a player was tackled by two players simultaneously as opposed to being tackled by a single tackler. 51 Tucker et al cite a small study by Hendricks et al which found weak evidence of an association between tackler proficiency and likelihood of concussion. 49 Burger et al did find evidence that improved tackle technique on the part of both the ball carrier and the tackler was associated with reduced risk of injury.48 Speed going into the tackle and force of impact 47 as well as tackle height52 also have an impact on injury.

A review of injury prevention strategies found little evidence that any had reduced the risk of injury from tackle as few had evaluated impact on injuries.53 In a systematic review, Fraas et al concluded that despite there being several concussion education and prevention 
"This is an accepted manuscript of an article published by BMJ Publishing Group in British Journal of Sports Medicine, available online at http://dx.doi.org/10.1136/bjsports-2016$\underline{096996}$ It is not the copy of record."

programmes across various country Rugby Unions, there is little evidence to support their effectiveness.54 The South African BokSmart programme may influence player's attitudes and may be associated with a reduction in catastrophic injury at the junior level.55 56 There is a need for proper evaluation of injury prevention programmes such as the secondary concussion prevention scheme HEADCASE, in the UK and Ireland.

Tucker et al state that the impact 'removing the tackle at an early age may have on injury risk later in the participation cycle is unknown'. A recent systematic review and metaanalysis from Canada found that rule changes disallowing body checking in Pee Wee (11 and 12 year old) ice hockey, where a player deliberately makes contact with an opposing player to separate them from the ice puck, has led to a $67 \%$ reduction, incidence rate ratio 0.33 (95\% $\mathrm{Cl} 0.25$ to 0.45$)$, in concussion risk.57 The evidence for other strategies to reduce concussion risk in sport including protective equipment (helmets, headgear and mouthguards), training and fair play rules is either weak or conflicting.57 Tucker et al refer to a large Canadian study on ice hockey involving nearly 2000 players aged 13-14 years which found that those previously exposed to 'body checking' had a reduced risk of injury requiring 7 days of time loss, although this was only borderline significant, incidence rate ratio 0.67 (95\% $\mathrm{Cl} 0.46$ to 0.99$) .58$ There was however no evidence of any association found between prior experience of body checking and injury overall, concussion overall or concussion resulting in $>10$ days of time loss.58 There are no studies from rugby which have analysed the effect of age of introduction of tackle on injury rates.

The numbers of children going on to play rugby 'reduce dramatically' at 18 years.59 Therefore, perfecting tackle technique for the long term is of little benefit. A survey conducted in a Scottish Borders rugby playing district among keen club players found that $19 \%$ of the reasons given by under 20 players for stopping playing were connected to rugby injury and a further $20 \%$ were connected to disillusionment with the game.60 There is no evidence that removing the tackle will have a negative impact on children who go on to play adult rugby.

Moreover, a training audit conducted in October 2015 in 24 Oxfordshire Rugby Football Schools Union-affiliated schools found that only $39 \%$ of current physical education (PE) teachers had any rugby coaching qualifications and only $32 \%$ had completed a concussion education module (for state schools this was $14 \%$, nine state schools had no teacher with concussion training). 61 Similarly, even in targeted schools for the RFU as part of the All Schools initiative, $31 \%$ of schools had received no coaching development training.62 Grappling with the merits of different tackle techniques and proficiency will not address the established risks and harms of the tackle in the laws of the game as they apply to school children.

\section{Conclusion}

Under the United Nations Convention on the Rights of the Child (Article 19), governments have a duty to protect children from risks of injury: 'States Parties shall take all appropriate legislative, administrative, social and educational measures to protect the child from all forms of physical or mental violence, injury or abuse, neglect or negligent treatment ...'.63 As a party to the Convention, the UK must ensure the safety of children. 
"This is an accepted manuscript of an article published by BMJ Publishing Group in British Journal of Sports Medicine, available online at http://dx.doi.org/10.1136/bjsports-2016$\underline{096996}$ It is not the copy of record."

A 2015 survey of predominantly private schools in England showed that 77\% of the 116 schools responding made rugby a compulsory sport.44 The Children's Commissioner for Wales, Sally Holland, states that in her view children should be given a choice of sport and no individual sport should be made compulsory. 64 Sport is part of the national curriculum in England, Scotland, Wales and Northern Ireland; however, the ministers have not made clear whether individual sports can be made compulsory at the individual school level. Children need to be given a choice of physical activity in school and their choices should be respected. The government should take steps to end compulsion and to outlaw dangerous elements of collision sports in children as it does for other school-based activities. It should ensure there is monitoring of all sports injuries in schools and in children. Government should commission a survey of all schools to ascertain what choice children actually have. Alternatives to collision rugby include a non-collision version such as tag rugby and many of the 40 sports listed as physical activities in the school curriculum for England.

Tucker et al provide no evidence which requires us to change our position on removing the tackle from school rugby. To echo Fuller and Drawer, we are proposing a 'compromise approach'.5 Rather than arguing for the entire rule structure of rugby union and rugby league to be changed, this compromise approach recognises children as a definable 'vulnerable group of athletes' with 'unique risks' and proposes 'specific measures' as a way of lessening the risk of injury in this group, at least where they are in a controllable environment, while at school. The call to remove the tackle and other harmful forms of contact from school rugby would reduce and mitigate the risk of injury in the vulnerable group of participants identified, school children.5

All the evidence available on injury in rugby shows the high risks of injury and that the tackle is where most injuries occur. Chief medical officers should advise ministers of this evidence and World Rugby and ministers should immediately take a cautionary approach to protect children from avoidable harms by removing the tackle from school rugby.

\section{References}

1 United Kingdom Interdepartmental Liaison Group on Risk Assessment (UK-ILGRA). The Precautionary Principle: Policy and Application 2002 www. hse. gov. uk/ aboutus/ meetings/ committees/ ilgra/ pppa. htm (accessed 22 Mar 2017).

2 Sport Collision Injury Collective. Open Letter: Preventing injuries in children playing school rugby 2016 www. sportcic. com/ resources/ Open\% 20Letter\% 20SportCIC\% 20March1st\% 202016. pdf (accessed 22 Mar 2017).

3 Tucker R, Raftery M, Verhagen E. Injury risk and a tackle ban in youth Rugby Union: reviewing the evidence and searching for targeted, effective interventions. A critical review. Br J Sports Med 2016;50:921-5.

4 Rugby Football Union. Regulations. www. englandrugby. com/governance/ regulations/ (accessed 22 Mar 2017).

5 Fuller C, Drawer S. The application of risk management in sport. Sports Med 2004;34:349-56.

6 Freitag A, Kirkwood G, Scharer S, et al. Systematic review of rugby injuries in children and adolescents under 21 years. Br J Sports Med 2015;49:511-9. 
"This is an accepted manuscript of an article published by BMJ Publishing Group in British Journal of Sports Medicine, available online at http://dx.doi.org/10.1136/bjsports-2016$\underline{096996}$ It is not the copy of record."

7 Kirkwood G, Parekh N, Ofori-Asenso R, et al. Concussion in youth rugby union and rugby league: a systematic review. Br J Sports Med 2015;49:506-10.

8 Bleakley C, Tully M, O'Connor S. Epidemiology of adolescent rugby injuries: a systematic review. J Athl Train 2011;46:555-65.

9 Papalia R, Tecame A, Torre G, et al. Rugby and Shoulder Trauma: A Systematic Review. Transl Med UniSa 2015;12:5-13.

10 Gardner A, Iverson GL, Levi CR, et al. A systematic review of concussion in rugby league. Br J Sports Med 2015;49:495-8.

11 Gardner AJ, Iverson GL, Williams WH, et al. A systematic review and meta-analysis of concussion in rugby union. Sports Med 2014;44:1717-31.

12 Williams S, Trewartha G, Kemp S, et al. A meta-analysis of injuries in senior men's professional Rugby Union. Sports Med 2013;43:1043-55.

13 McIntosh AS, McCrory P, Finch CF, et al. Head, face and neck injury in youth rugby: incidence and risk factors. Br J Sports Med 2010;44:188-93.

14 Palmer-Green DS, Stokes KA, Fuller CW, et al. Match injuries in English youth academy and schools rugby union: an epidemiological study. Am J Sports Med 2013;41:749-55.

15 Bahr R, Krosshaug T. Understanding injury mechanisms: a key component of preventing injuries in sport. Br J Sports Med 2005;39:324-9.

16 Burger N, Lambert MI, Viljoen W, et al. Tackle-related injury rates and nature of injuries in south african Youth Week tournament rugby union players (under-13 to under-18): an observational cohort study. BMJ Open 2014;4(8):e005556.

17 Collins CL, Micheli L, Yard EE, et al. Injuries sustained by high school rugby players in the United States, 2005-2006. Arch Pediatr Adolesc Med 2008;162:49-54.

18 Roberts SP, Trewartha G, England M, et al. Concussions and Head Injuries in English Community Rugby Union Match Play. Am J Sports Med 2017;45:480-7.

19 Kemp S Brooks J Cross M et al. England Professional Rugby Injury Surveillance Project: 2014-2015 season report. March 2016. www. englandrugby. com/ mm/ Document/ General/ General/ 01/31/ 72/ 86/ InjurySurveillanceReport_2014- 15_SINGLE_ 22Mar16_English. pdf (accessed 22 Mar 2017).

20 McCrory P, Meeuwisse WH, Aubry M, et al. Consensus statement on concussion in sport: the 4th International Conference on Concussion in Sport held in Zurich, November 2012. Br J Sports Med 2013;47:250-8.

21 Fuller CW, Taylor A, Raftery M. Epidemiology of concussion in men's elite Rugby-7s (Sevens World Series) and Rugby-15s (Rugby World Cup, Junior World Championship and Rugby Trophy, Pacific Nations Cup and English Premiership). Br J Sports Med 2015;49:478-83.

22 Sariaslan A, Sharp DJ, D'Onofrio BM, et al. Long-Term Outcomes Associated with traumatic brain Injury in Childhood and Adolescence: a Nationwide Swedish Cohort Study of a wide Range of Medical and Social Outcomes. PLoS Med 2016;13(8):e1002103.

23 Miller JH, Gill C, Kuhn EN, et al. Predictors of delayed recovery following pediatric sports-related concussion: a case-control study. J Neurosurg Pediatr 2016;17:491-6. 24 Rugby Football Union. This is England Women's Rugby, 2014. www. englandrugbyfiles. com/ women- and- girls/ (accessed 22 Mar 2017). $25 \mathrm{Li} \mathrm{Y,} \mathrm{Li} \mathrm{Y,} \mathrm{Li} \mathrm{X,} \mathrm{et} \mathrm{al.} \mathrm{Head} \mathrm{Injury} \mathrm{as} \mathrm{a} \mathrm{risk} \mathrm{factor} \mathrm{for} \mathrm{Dementia} \mathrm{and} \mathrm{Alzheimer's} \mathrm{Disease:}$ 
"This is an accepted manuscript of an article published by BMJ Publishing Group in British Journal of Sports Medicine, available online at http://dx.doi.org/10.1136/bjsports-2016096996 It is not the copy of record."

A Systematic Review and Meta-Analysis of 32 Observational Studies. PLoS One 2017;12:e0169650.

26 Kirkwood G, Hughes TC, Pollock AM. Injury surveillance in Europe and the UK. BMJ 2014;349:g5337.

27 Pollock AM, Kirkwood G. Removing contact from school rugby will not turn children into couch potatoes. Br J Sports Med 2016;50:963-4.

28 Fuller CW, Molloy MG, Bagate $C$, et al. Consensus statement on injury definitions and data collection procedures for studies of injuries in rugby union. $\mathrm{Br} \mathrm{J}$ Sports Med 2007;41:328-31.

29 Haseler CM, Carmont MR, England M. The epidemiology of injuries in English youth community rugby union. Br J Sports Med 2010;44:1093-9.

30 McIntosh AS. Rugby injuries. Med Sport Sci 2005;49:120-39.

31 Durie RM, Munroe AD. A prospective survey of injuries in a New Zealand Schoolboy rugby population. N. Z.. J. Sports Med 2000;28:84-91.

32 Davidson R, Kennedy M, Kennedy J, et al. Casualty room presentations and schoolboy rugby union. Med J Aust 1978;1:247-9.

33 Junge $A$, Cheung $K$, Edwards $T$, et al. Injuries in youth amateur soccer and rugby players--comparison of incidence and characteristics. Br J Sports Med 2004;38:168-72.

34 Nicol A, Pollock A, Kirkwood G, et al. Rugby union injuries in Scottish schools. J Public Health 2011;33:256-61.

35 Pringle RG, McNair P, Stanley S. Incidence of sporting injury in New Zealand youths aged 6-15 years. Br J Sports Med 1998;32:49-52.

36 Roux CE, Goedeke R, Visser GR, et al. The epidemiology of schoolboy rugby injuries. S Afr Med J 1987;71:307-13.

37 Garraway WM, Lee AJ, Hutton SJ, et al. Impact of professionalism on injuries in rugby union. Br J Sports Med 2000;34:348-51.

38 Henderson NJ. Impact of professionalism on injuries in rugby. Br J Sports Med 2000;34:473-a-473.

39 Quarrie KL, Chalmers DJ. Impact of professionalism on injuries in rugby union. $\mathrm{Br} \mathrm{J}$ Sports Med 2001;35:450.

40 Silver JR. Professionalism and injuries in rugby union. Br J Sports Med 2001;35:138a-138.

41 Roberts SP, Trewartha G, England M, et al. Epidemiology of time-loss injuries in English community-level rugby union. BMJ Open 2013;3:e003998.

42 Rice SG; American Academy of Pediatrics Council on Sports Medicine and Fitness.

Medical conditions affecting sports participation. Pediatrics 2008;121:841-8.

43 Department for Education. GCSE PE activity list, January 2015. www. gov. uk/ government/ uploads/ system/ uploads/ attachment_data/ file/ 447738/ GCSE_activity_ list_for_PE.pdf (accessed 22 Mar 2017).

44 Nyiri PRe: The unknown risks of youth rugby.BMJ 2015 www. bmj. com/ content/ 350/ bmj. h26/ rr-9 (accessed 22 Mar 2017).

45 Pfister T, Pfister K, Hagel B, et al. The incidence of concussion in youth sports: a systematic review and meta-analysis. Br J Sports Med 2016;50:292-7.

46 Spinks AB, McClure RJ. Quantifying the risk of sports injury: a systematic review of activity-specific rates for children under 16 years of age. Br J Sports Med 
"This is an accepted manuscript of an article published by BMJ Publishing Group in British Journal of Sports Medicine, available online at http://dx.doi.org/10.1136/bjsports-2016$\underline{096996}$ It is not the copy of record."

2007;41:548-57.

47 Fuller $\mathrm{CW}$, Ashton T, Brooks JH, et al. Injury risks associated with tackling in rugby union. Br J Sports Med 2010;44:159-67.

48 Burger N, Lambert MI, Viljoen W, et al. Tackle technique and tackle-related injuries in high-level South African Rugby Union under-18 players: real-match video analysis. $\mathrm{Br} J$ Sports Med 2016;50:932-8.

49 Hendricks S, O'connor S, Lambert $M$, et al. Contact technique and concussions in the South African under-18 Coca-Cola Craven Week Rugby tournament. Eur J Sport Sci 2015;15:557-64.

50 Quarrie KL, Raftery M, Blackie J, et al. Managing player load in professional rugby union: a review of current knowledge and practices. Br J Sports Med 2017;51:421-7.

51 McIntosh AS, Savage TN, McCrory P, et al. Tackle characteristics and injury in a cross section of rugby union football. Med Sci Sports Exerc 2010;42:977-84.

52 Quarrie KL, Hopkins WG. Tackle injuries in Professional Rugby Union. Am J Sports Med 2008;36:1705-16.

53 Freitag A, Kirkwood G, Pollock AM. Rugby injury surveillance and prevention programmes: are they effective? BMJ 2015;350:h1587.

54 Fraas MR, Burchiel J. A systematic review of education programmes to prevent concussion in rugby union. Eur J Sport Sci 2016;16:1212-8.

55 Brown JC, Gardner-Lubbe S, Lambert MI, et al. The BokSmart intervention programme is associated with improvements in injury prevention behaviours of rugby union players: an ecological cross-sectional study. Inj Prev 2015;21:173-8.

56 Brown JC, Verhagen E, Knol D, et al. The effectiveness of the nationwide BokSmart rugby injury prevention program on catastrophic injury rates. Scand J Med Sci Sports 2016;26:221-5.

57 Emery CA, Black AM, Kolstad A, et al. What strategies can be used to effectively reduce the risk of concussion in sport? Br J Sports Med 2017.

58 Emery C, Kang J, Shrier I, et al. Risk of injury associated with bodychecking experience among youth hockey players. CMAJ 2011;183:1249-56.

59 Mactaggart M. Insights RFU. A paper examining participation, drop out and recommended solutions to aid in retaining and bringing back 16 to 24 year old rugby players. www. academia. edu/ 8207408/ Rugby_Player_Participation_Insights (accessed 22 Mar 2017).

60 Lee AJ, Garraway WM, Hepburn W, et al. Influence of rugby injuries on players' subsequent health and lifestyle: beginning a long term follow up. $\mathrm{Br} J$ Sports Med 2001;35:38-42.

61 Oxfordshire Rugby Football Schools Union. Training Audit 2015;2015 www. oxonrugbyschools. co. uk/ resources/ ORFSU\% 20Training\% 20Report\% 20Dec\% 202015\% 20. pdf.

62 Shibli S, Moore R, Barrett D, et al. All Schools monitoring Report. Autumn Term. Sheffield Hallam University. Sport Industry Research Centre 2015.

63 UNICEF. United Nations Convention on the Rights of the Child, 1989. www. unicef. org. uk/ crc (accessed 22 Mar 2017).

64 Holland S; Response to SCIC open letter, Sally Holland Children's Commissioner for Wales 29th March. 2016. 
"This is an accepted manuscript of an article published by BMJ Publishing Group in British Journal of Sports Medicine, available online at http://dx.doi.org/10.1136/bjsports-2016$\underline{096996}$ It is not the copy of record."

65 British Medical Journal. Poll Archive. 2015. www. bmj. com/ about- bmj/ poll- archive (accessed 22 Mar 2017).

66 Davidson RM. Schoolboy Rugby injuries, 1969-1986. Med J Aust 1987;147:119-20.

67 Fuller CW, Molloy MG, Marsalli M. Epidemiological study of injuries in men's international under-20 rugby union tournaments. Clin J Sport Med 2011;21:356-8. 68 Nathan M, Goedeke R, Noakes TD. The incidence and nature of rugby injuries experienced at one school during the 1982 rugby season. S Afr Med J 1983;64:132-7.

69 Sparks JP. Rugby football injuries, 1980-1983. Br J Sports Med 1985;19:71-5. 70 IntHout J, loannidis JP, Rovers MM, et al. Plea for routinely presenting prediction intervals in meta-analysis. BMJ Open 2016;6:e010247. 